\title{
М. А. Липкин
}

\section{СОВЕТ ЭКОНОМИЧЕСКОЙ ВЗАИМОПОМОЩИ И СОВРЕМЕННЫЕ ТРЕНДЫ В ИЗУЧЕНИИ ХХ ВЕКА: К 70-ЛЕТИЮ ОБРАЗОВАНИЯ СЭВ*}

Совет экономической взаимопомощи - один из столпов единства «Восточного блока» в период холодной войны, сердце «мировой системы социализма», согласно геополитическому видению капитанов восточной альтернативы капиталистической глобализации в период 1950-х - 1980-х гг. Со времени роспуска этой организации в 1991 г. его история пережила периоды забвения и возрождения интереса. Последнее связано как с открытием исторических архивов, так и с формированием новых методологических подходов и, самое главное, нового поколения историков, не связанных своим личным опытом с периодом существования этой организации и готовых проводить исследования «с чистого листа», в отличие от поколения современников, чей горизонт видения зачастую был ограничен узким кругом источников, личным опытом и вкусовыми пристрастиями ушедшей эпохи.

Примечательно, что применительно к истории СЭВ архивы не являлись главным сдерживающим фактором. Фонд СЭВ в Российском государственном архиве экономики был доступен и десять лет назад. Фонды государств-участников СЭВ стран Восточной Европы - были открыты и того раньше, центральным среди них считается немецкая коллекция документов, оставшаяся в наследие от ГДР. Однако и там волна исследовательского интереса, выразившаяся в интенсификации конференций, публикаций и исследовательских грантов, поднялась лишь в конце 2000-х гг. «Будителем» интереса стала немецкая историографическая школа, возглавившая процесс реинтеграции поля истории СЭВ в историю «глобальной холодной войны». Если в 1990-е, несмотря на открытие архивов, было практически невозможно найти аспиранта, работающего по теме СЭВ, то в 2010-х гг. это стало модным трендом.

Статья подготовлена в рамках гранта РНФ № 17-18-01728 «Мировая система социализма и глобальная экономика в середине 1950-х - середине 1970-х годов: эволюция теории и практики экономического и технологического лидерства СССР».

(C) М. А. Липкин, 2019 
С другой стороны, почву для интереса к СЭВ стали прощупывать историки западноевропейской интеграции, которых волновала тема восприятия ЕЭС в Восточной Европе ${ }^{1}$. Об этом говорят тематики докладов на ежегодных коллоквиумах и семинарах, объединивших новое поколение исследователей двух молодежных ассоциаций: континентальной («Международная сеть молодых исследователей европейской интеграции» (RICHIE, Франция)) и островной британской («Исследовательское общество истории европейской интеграции» (HEIRS)). Возможно, именно этим объясняется то, что тема отношений СЭВ и ЕЭС наиболее развита среди новой волны историков.

Как отмечал еще в 2010 г. один из исследователей СЭВ Мартин Дангерфилд, 50-летие и 60 -летие организации прошли практически в полном забвении среди историков ${ }^{2}$ И вдруг в 2019 г. 70-летие СЭВ привело к активизации сессий и конференций, не в последнюю очередь в различных исследовательских центрах Российской Федерации (международные конференции в Калининграде, Челябинске и Москве) ${ }^{3}$.

В чем причина такого исследовательского бума и что нового принесли с собой «нулевые» годы в, казалось бы, задвинутую далеко на полку истории тему экономических институтов Восточного блока?

Представляется, что отчасти этот интерес связан с возрождением внимания к плановой экономике на фоне новой эры турбулентности в финансовой и торговой сферах современного мирового рынка. Если в 1990-е гг. СЭВ служил «пугалом» для новых европейцев, примером краха Восточного блока, участия в нем стыдились «новоевропейцы», готовившиеся войти в ЕС (как и самого термина «Восточная Европа» и прочих напоминаний о социалистическом периоде своей истории), то по мере спада триумфализма и одностороннего видения хода и итогов «холодной войны», по мере роста противоречий между «старыми» и «новыми» членами Евросоюза, желания у «новоевропейцев» сравнить влияние и роль своей страны в ЕС с тем положением, которое они занимали в рамках СЭВ, стал формироваться общественный и социальный запрос на более внимательное изучение «плюсов» и «минусов» плановой экономики.

В условиях мирового экономического кризиса 2008 г. разными странами стали использоваться отдельные элементы планирования. У «старых европейцев» возрос интерес к социокультурным корням «новых европейцев», с которыми после расширения ЕС в 2004 и 2007 гг. столкнулись основатели «объединенной Европы», да и в самой ФРГ - центральной стране для всего Евросоюза - прошел период

${ }^{1}$ Lipkin M. A Struggle between Eastern and Western Models of «Integration» in the First Half of the 1970s // Quelle(s) Europe(s)? Nouvelles approches en histoire de l'intégration européenne / Ed. by Katrin Rucker \& Laurent Warlouzet. Brussels, 2006. P. 299-310.

${ }^{2}$ Muller $U$. Introduction: Failed and forgotten? New Perspectives on the history of the Council for Mutual Economic Assistance // Comparativ. Zeitschrift fur globalgeschichte und vergleichende gesellschaftsforschung. 2017. Heft 5/6. P. 8.

${ }^{3}$ Международные конференции: «СЭВ: опыт формирования мирового экономического сообщества. К 70-летию со дня основания» (31.01-01.02.2019 г., БФУ им. И. Канта, Калининград); «Наследие кооперации СЭВ: Конференция по истории политической экономии социалистического лагеря» (11-13.05.2019, ЧелГУ, Челябинск); «Мировая система социализма: глобальные и региональные аспекты. К 70-летию образования СЭВ» (03-04.10.2019, ИВИ РАН, Москва). 
неформального запрета на историю ГДР, закончился болезненный этап интеграции восточногерманских историков и их тематик после объединения страны в 1989 г. в общегерманский историографический дискурс.

К примеру, с 2011 г. позиционирующая себя как некоммерческая организация «Евроакадемия» ежегодно проводит международные конференции «Изобретая заново Восточную Европу» (Re-inventing Eastern Europe) в целях как интеграции восточноевропейской элиты, так и лучшего понимания культурного кода последней, который явно отличается от элиты стран-основателей «единой Европы».

Так же не случайно в рамках крупных многолетних грантовых проектов Евросоюза «Горизонт 2020» был поддержан международный исследовательский проект на базе Европейского Института-Университета во Флоренции «Смотря на Запад: Европейские социалистические режимы перед вызовом панъевропейского сотрудничества и Европейского Сообщества (ПанЕвро70е)» во главе с профессором Федерико Ромеро. Цель гранта - именно анализ взглядов и политического дискурса в среде восточноевропейской элиты по проблеме сотрудничества с Западной Европой вообще и со структурами Европейского Сообщества в частности. Чтобы были понятны сложность и важность этой темы, достаточно сказать, что одна из ведущих исследовательниц новой волны - финский историк Суви Кансикас - считает неудачу переговорного процесса о взаимном признании и установлении выгодных отношений между СЭВ и ЕС главной причиной падения интереса к этому интеграционному объединению со стороны стран-членов в 1980-х гг. ${ }^{4}$

Одной из центральных работ, послужившей отправной точкой для этого гранта, стал тематический номер журнала «Европейский обзор истории», подготовленный в тандеме Анжелой Романо и Федерико Ромеро из Европейского институтауниверситета в 2014 г. под названием «Европейские социалистические режимы перед лицом глобализации и европейского сотрудничества: дилеммы и ответы», в котором в числе прочих были статьи на тему СЭВ5

Другой очевидной причиной возрождения темы СЭВ на различных конгрессах и конференциях в 2010-х гг. стал запрос на понимание современной конфигурации международных отношений, поиск альтернативных моделей глобализации. И тут внимание фокусируется на глобальных связях этой организации в 1960-х - 1980-х гг., связях между «вторым» (социалистическим) и «третьим» (развивающимся) мирами.

Здесь тема СЭВ появляется как часть более общей тематики глобального влияния социализма на развитие мировой экономики во второй половине XX столетия. Еще в 2010 г. на конференции британской ассоциации по истории европейской интеграции (HEIRS), посвященной холодной войне, была поднята тема альтернативных проектов в Восточной Европе. А в 2014 г. университет Эксетера во главе с профессором Джеймсом Марком выиграл крупнейший гуманитарный грант (мегагрант по российским меркам) от Совета по искусству и гуманитарным наукам Великобритании «Социализм становится глобальным. Связи периода холодной войны между “вторым” и “третьим” мирами» ${ }^{6}$.

${ }^{4}$ Kansikas S. Paper, presented at the BASEES Annual conference. Cambridge, 2019.

${ }^{5}$ European review of History — Revue Européenne d'Histoire. 2014. Vol. 21. No. 2.

${ }^{6}$ URL: http://socialismgoesglobal.exeter.ac.uk (дата посещения - 20.07.2019). 
Проект объединил усилия профессионалов из восьми университетов (из которых только три - Университет Эксетера, Университетский колледж Лондона и Оксфорд собственно британские, но они, конечно, задавали тон всему проекту). Исследователи отмечали полное отсутствие современного понимания влияния экспорта социализма на развивающиеся страны и обратного влияния - через студентов, стажеров, инструкторов, академических исследователей и т. д. на страны Восточного блока по мере развития процессов деколонизации и активной роли СССР и его союзников. Проект прямо не был направлен на изучение СЭВ, но в своих докладах и публикациях его участники так или иначе способствовали развитию этой темы, т. к. СЭВ с середины 1950-х гг. позиционировался как сердце «мировой системы социализма», а в 1970-е гг. активно включился в борьбу за «новый мировой экономический порядок». Этому посвящена одна из центральных публикаций этого проекта — доступная только онлайн статья Джеймса Марка и Тобиаса Рупрехта «Социалистический мир в глобальной истории. От аутсайдера до жертвы и со-продюсера» ${ }^{7}$. Более продвинутая книжная версия «Альтернативные глобализации: Восточная Европа и постколониальный мир» в соавторстве с Артемом Калиновским и Штефи Марунг ожидается к выходу в 2020 г. в издательстве университета Индианы

Прорывной, хотя и не сразу замеченной историками (здесь, как и в случае с Оскаром Санчес-Сибони, явно прослеживается скрытый поколенческий конфликт) является статья молодого французского историка Симона Годдарда и его коллеги из Голландии Лауриен Крамп о СЭВ как о краеугольном для существования всей восточной ойкумены форуме социалистических стран ${ }^{9}$. Принципиальным моментом является то, что они намеренно отказались от оценки СЭВ через призму сравнений с Европейским Сообществом. Таким образом, СЭВ рассматривается не как неудавшееся наднациональное плановое квазигосударство-антипод ЕС, а как имевшая иные функции крайне важная структура — международный многосторонний форум в системе отношений восточноевропейских стран ${ }^{10}$. По сути, они ставят вопрос о том, что было важнее: официальные коммюнике и принимаемые планы (по которым историки ранее судили о роли СЭВ) или открываемые заново по ранее совсекретным документам закрытые каналы общения под вывеской СЭВ восточноевропейских (а с расширением СЭВ в 1962 и начале 1970-х гг. и внеевропейских членов) политических элит соцстран на политические, экономические, социальные и прочие темы.

Параллельно тандему Годдард-Крамп работала группа исследователей из Лейпцига на базе Центра истории и культуры Восточной и Средней Европы Лейпцигского

${ }^{7}$ Mark J., Rupprecht T. The Socialist World in Global History. From Absentee to Victim to Co-Produce // Matthias Middell (ed.) The Practice of Global History. European Perspectives, London: Bloomsbury, 2019. Pp. 81-114. (URL: https://www.academia.edu/37498808/The Socialist_World_in_Global_History._From_Absentee_to_Victim_to_Co-Producer (дата посещения - 20.07.2019)).

${ }^{8}$ URL: http://www.iupress.indiana.edu/product_info.php?cPath=1037_3025_10431\&produ cts_id=809955 (дата посещения — 20.07.2019).

${ }^{9}$ Crump L., Godard S. Reassessing Communist International Organizations: A Comparative Analysis of COMECON and the Warsaw Pact in relation to their Cold War Competitors // Contemporary European History. 2017. Vol. 27. No 1. P. 1-25.

${ }^{10}$ Crump L., Godard S. Reassessing Communist International Organizations... P. 1-25. 
университета во главе с профессорами Уве Мюллером и Дагмарой Яесьняк-Куаст. Они организовали в ноябре 2012 г. первую крупную международную конференцию в Западной Европе по истории СЭВ «Экономические связи в Восточной и Центральной Европе и место СЭВ в глобальной экономике (1949-1991)». Казалось бы, мало кем замеченная, она вылилась в существенно доработанную публикацию тематический номер журнала «Компаратив» под заголовком «Ревизия СЭВ. Интеграция в восточном блоке и переплетения с глобальной экономикой» ${ }^{11}$. Этот номер показал широчайший исследовательский диапазон и потенциал исследований, связанных с этой организацией.

Рассказ о современной историографии СЭВ был бы не полным без небольшого экскурса в ту область знаний, откуда, собственно, и появилась советология и «сэвология»: историю холодной войны. Эта область сама по себе тоже, казалось, исчерпала свой потенциал в начале 2000-х гг, но сейчас переживает новый бум. Применительно к истории СЭВ центральным оказалось влияние глобальной истории на проблему «Восток-Запад». Здесь сказался отложенный эффект как от ставшей классической работы профессора Арне Вестада «Глобальная холодная война», так и критиковавшего его и других исследователей старого поколения молодого историка Оскара Санчеса-Сибони, автора нашумевшей книги «Красная глобализация. Политическая экономия советской холодной войны от Сталина до Хрущева» ${ }^{12}$. Хотя ни в одной из этих книг нет разделов именно по истории СЭВ, они задают тон всем современным исследованиям по экономической истории второй половины ХХ в. И за счет интеграции темы «Север-Юг» в традиционные книги по противостоянию по оси «Запад-Восток», и за счет пересмотра традиционных убеждений в автаркичности и самодостаточности стран Восточного блока. Во многом благодаря этим работам появились новые методологические подходы, которые позволили интегрировать советскую и - шире - социалистическую историю в проблемное поле глобальных процессов ХХ в.

Интересно, что, несмотря на возрождение интереса к СЭВ, за рассматриваемый период не появилось ни одной фундаментальной работы монографического жанра в духе «новой холодной войны» - с акцентом на документальные источники, а не на идеологические штампы и мемуарную литературу.

Классической работой видного представителя старого поколения «советологов» среди историков считается монография Рэндела Стоуна «Сателлиты и комиссары. Стратегия и конфликт в торговой политике советского блока», изданная Принстенским университетом в 1996 г. $^{13}$ Долгое время считалось, что этот труд закрыл собой целую тему - ничего более фундаментального долгое время не появлялось с той поры.

${ }^{11}$ Comparativ: Zeitschrift fur Globalgeschichte und Vergleichende gesellschaftsforschung. Leipzig. 2017. Vol. 27. № 5-6: Comecon Revisited. Integration in the Eastern Bloc and Entaglements with the Global Economy. 198 p.

${ }_{12}$ Sanchez-Sibony $O$. Red Globalization. The political economy of the Soviet Cold War from Stalin to Khrustchev. Cambridge, 2014. - Подробнее см.: Липкин М. А. Глобальное прочтение истории СССР: дискуссии вокруг «Красной глобализации» Оскара Санчеса-Сибони // Российская история. 2016. № 1. С. 131-144.

${ }^{13}$ Stone $R$. W. Satellites and commissars: strategy and conflict in the politics of Soviet-block trade. Princeton, 1996. 
Это исследование построено преимущественно на жанре устных интервью огромной работе, проделанной автором по опросу бывших чиновников и политиков стран Восточного блока по горячим следам - сразу после роспуска организации в 1991 г. Уже в нем можно обнаружить намеки на необходимость пересмотра роли СЭВ и малых стран в рамках Восточного блока, однако без серьезного анализа архивов и базовых документов эти намеки оставались без дальнейшего развития. Устная история безусловно интересна, но все же является вторичной по отношению к первичным источникам.

В этом плане гораздо фундаментальнее с источниковедческой точки зрения выглядят три диссертации и связанные с ними доклады и статьи: финской исследовательницы Суви Кансикас (защитившейся в 2012 г. в Хельсинкском университете по теме «Торговые блоки и холодная война: СЭВ и вызов ЕС: 1969-1976»); Эрика Радиша из университета Бохума, посвятившего свою работу анализу действий экономических советников на примере Венгрии (по теме «СССР и Венгрия в Совете экономической взаимопомощи: имперские структуры или социалистическая экономическая интеграция?») и по теме энергетической интеграции Фалка Фладе из Европейского университета Виадрина во Франкфурте-на-Одере «Энергетические инфрастуктуры в Восточном блоке. Польша и создание транснациональных электрических, нефтяных и газовых магистральных систем» ${ }^{14}$.

Наиболее активной исследовательницей нового поколения «сэвоведов» является именно Суви - за прошедший с момента написания диссертации период она организовала огромное количество сессий на различных конференциях и активно публикуется, эволюционируя от темы СЭВ-ЕС к собственно истории СЭВ ${ }^{15}$. Слабым звеном указанных работ является то, что хотя они и привлекают частично российские архивы, центральными для них являются более доступные и близкие географически восточногерманские файлы, в то время как для понимания всех хитросплетений механизма СЭВ и нюансов правленых и неправленых версий одних и тех же документов, конечно, надо проработать ключевые фонды, хранящиеся в Москве.

Казалось бы, с точки зрения архивов, на более выигрышных стартовых позициях находятся российские историки. Однако здесь негативно сказывается как поколенческий разрыв, так и общие проблемы развития гуманитарных наук в Российской Федерации. В 1990-е - начале 2000-х гг. тема СЭВ спорадически развивалась по инерции специалистами-практиками, связанными с академическими институтами, занимавшимися проблемами стран-членов в 1980-е гг. Это бывший Институт экономики мировой социалистической системы АН СССР (1960г.), преобразованный в 1990-е в Институт международных экономических и политических

${ }^{14}$ Kansikas $S$. Socialist countries face the European Community. Soviet-bloc controversies over East-West trade. Frankfurt am Main, 2014; Flade F. Energy infrastructures in the Eastern bloc. Poland and the construction of transnational electricity, oil and gas transmission systems. A Thesis, submitted to the faculty of Business administration and economics of the European University Viadrina in Franfurt (Oder). Frankfurt (Oder), 2017.

${ }_{15}$ Особенно стоит отметить характерную для эволюции историков ЕС к историкам СЭВ организованную С. Кансикас в Хельсинки в октябре 2017 г. международную конференцию «Competing visions: European integration beyond the EC/EU». 
исследований РАН, позднее объединенный с Институтом экономики $\mathrm{PAH}^{16}$, и бывший институт Славяноведения и балканистики АН СССР, с 1997 г. - Институт славяноведения $\mathrm{PAH}^{17}$. Среди наиболее заметных работ по сэвовской тематике следует отметить изданный Институтом экономики первый том из серии «ЦентральноВосточная Европа во второй половине XX века» (2000 г.), а также организованную в 2009 г. совместно Российским государственным архивом экономики и Институтом экономики РАН единственную юбилейную конференцию «СЭВ: советский проект экономической интеграции» и изданный по ее итогам сборник материалов ${ }^{18}$. Также важно отметить единственную малотиражную, но зато комплексную - по всему периоду существования СЭВ - монографию О. Н. Широкова «СЭВ в мировой экономике: современные оценка и проблемы функционирования и значения. Вопросы истории, методологии и историографии» ${ }^{19}$.

С 2010-х гг. стали появляться отдельные публикации и выступления исследователей новой волны, чьи усилия были поддержаны грантами Российского научного фонда (проект РНФ №17-18-01728 «Мировая система социализма и глобальная экономика в середине 1950-х - середине 1970-х годов: эволюция теории и практики экономического и технологического лидерства СССР» под руководством д-ра ист. наук М. А. Липкина на базе Института всеобщей истории РАН и проект РНФ № 17-78-10070 «Изучение опыта реализации проектов долевого участия в рамках Совета экономической взаимопомощи как инструмента интеграции экономик с высокой ролью государственного сектора» под руководством канд. ист. наук А. А. Попова на базе Южно-Уральского государственного университета).

Что показывает кропотливая исследовательская работа в российских архивах? Во-первых, документы говорят об огромном внимании, которое уделяли лидеры соцстран, включая СССР, теме экономики, в том числе внешней экономики, корреляции между планированием развития внешнеэкономических связей и внутриэкономических проектов модернизации, особенно в послесталинский период. В отличие от бытовавших в 1990-е гг. представлений, речь не сводилась только к внешней торговле. Постоянные комиссии, а также создававшиеся по мере необходимости экспертные группы занимались сложными вопросами импорта-экспорта образования, технологий, развития международного права и т. д. Огромный малоисследованный пласт представляет собой история совместных многосторонних предприятий и объединений СЭВ. Во-вторых, поражает свобода маневра, существовавшая особенно для малых

${ }_{16}$ Орлик И. И. СЭВ - «Общий рынок»: первые шаги к сближению двух интеграций // К 60-летию Совета экономической взаимопомощи. Единая Европа: прошлое и настоящее экономической интеграции. М., 2009. С. 223-238.

${ }_{17}^{17}$ Гибианский Л. Я. К истории возникновения коллективных структур советского блока: образование Совета экономической взаимопомощи // Славянство, растворенное в крови...: В честь 80-летия со дня рождения члена-корреспондента РАН В. К. Волкова (1930-2005). M., 2010. C. 325-348.

${ }^{18}$ Центрально-Восточная Европа во второй половине XX века. Т. 1: Становление «реального социализма» (1945-1965). М., 2000; К 60-летию Совета экономической взаимопомощи. Единая Европа: прошлое и настоящее экономической интеграции. М., 2009.

${ }_{19}^{19}$ Широков О. Н. СЭВ в мировой экономике: современные оценка и проблемы функционирования и значения. Вопросы истории, методологии и историографии. М., 2005. 
стран в рамках СЭВ. Откровенность в общении представителей за закрытыми дверями позволяла выявить накапливавшиеся конфликты и сглаживать их различными путями. В то же время именно гибкость и удивительная мягкость и дипломатичность советских представителей (на фоне нередко провокационных и откровенно резких демаршей тех или иных стран-членов в СЭВ) приводили к постоянным модификациям тех планов, что пытался реализовать через эту организацию СССР. Парадокс заключается в том, что, несмотря на, казалось бы, тоталитарную природу восточноевропейских режимов, СЭВ демонстрировал больший демократизм, нежели иные структуры ЕС. Это видно не по коммюнике и протоколам встреч, которыми оперировали большинство историков рубежа веков. Это видно также по не выходившим наружу дискуссиям в рамках организации. Нежелавшие поступиться своим суверенитетом страны-члены (под который часто маскировался национальный эгоизм), противившиеся введению наднациональности в Восточной Европе, в итоге настаивали на своем и заставляли СССР постоянно идти на уступки и компромиссы ${ }^{20}$.

Очевидно, что в год 70-летия образования СЭВ история этой организации переживает исследовательский бум в мировой историографии. Примечательно, что хотя в академической среде принято оценивать историографию в первую очередь по монографиям, применительно к СЭВ не было написано ни одной крупной работы с 1990 -х гг. ни в России, ни за рубежом. Историографический дискурс сместился в область статей, диссертаций и международных конференций. В этом трудность и специфика анализа современной ситуации с изучением экономической истории Восточного блока. Проблемное поле СЭВ переживает новый этап, связанный даже не столько с открытием архивов, сколько с приходом новой волны исследователей, заинтересованных в объективном изучении феномена СЭВ с позиций транснациональной и глобальной истории, ищущих ответы на вопросы сегодняшнего дня о возможных альтернативах капиталистической глобализации, основанной на прошловековой базе институтов Бреттон-Вудской модели.

Информация о статье

Статья подготовлена в рамках гранта РНФ № 17-18-01728 «Мировая система социализма и глобальная экономика в середине 1950 -х - середине 1970-х годов: эволюция теории и практики экономического и технологического лидерства СССР».

Автор: Липкин, Михаил Аркадьевич — доктор исторических наук, член-корреспондент РАН, директор, Институт всеобщей истории Российской Академии наук, Москва, Россия, OrcID 0000-0002-7717-6392, ResearcherID R-9304-2016, Scopus ID 57059972700, SPIN-код 2211-0732, e-mail: mli@igh.ru

Заголовок: Совет экономической взаимопомощи и современные тренды в изучении XX века: к 70-летию образования СЭВ

Резюме: Статья посвящена анализу современного состояния исследований по истории Совета экономической взаимопомощи. Анализируя публикации, диссертации и научные докладыза последние два десятилетия, автор показывает, что после самороспуска организации в 1991 г. ее история была предана незаслуженному забвению. Новый интерес проснулся в 2010-х гг., чему способствовали формирование социального запроса на понимание экономической природы восточноевропейских

${ }_{20}$ Липкин М. А. 1) «Мировой кооператив народов»: Совет экономической взаимопомощи, который пытался построить Н. С. Хрущев // Новый исторический вестник. 2017. № 4. С. 121-144; 2) «Мы идем с открытым забралом на разговор с “Общим рынком”»: История переговоров СЭВ и ЕЭС об основах отношений в 1972-1979 годах // Новый исторический вестник. 2018. № 4 (58). С. 101-135. 
стран и появление новых методологических подходов нового поколения историков. Проблемное поле СЭВ переживает новый этап, связанный даже не столько с открытием архивов, сколько с приходом новой волны исследователей, заинтересованных в объективном изучении феномена СЭВ с позиций транснациональной и глобальной истории, ищущих ответы на вопросы сегодняшнего дня о возможных альтернативах капиталистической глобализации, основанной на базе институтов Бреттон-Вудской модели ХХ в.

Ключевые слова: СЭВ, плановая экономика, экономическая глобализация, социализм, капитализм, холодная война, европейская интеграция, СССР, Восточная Европа, историография, глобальная история

\section{Литература, использованная в статье:}

Гибианский, Леонид Янович. К истории возникновения коллективных структур советского блока: образование Совета экономической взаимопомощи // Славянство, растворенное в крови...: В честь 80-летия со дня рождения члена-корреспондента РАН В. К. Волкова (1930-2005). Москва: Институт славяноведения РАН, 2010. С. 325-348.

Липкин, Михаил Аркадьевич. «Мы идем с открытым забралом на разговор с “Общим рынком”»: История переговоров СЭВ и ЕЭС об основах отношений в 1972-1979 годах // Новый исторический вестник. 2018. № 4 (58). С. 101-135.

Липкин, Михаил Аркадьевич. «Мировой кооператив народов»: Совет экономической взаимопомощи, который пытался построить Н. С. Хрущев // Новый исторический вестник. 2017. № 4. С. 121-144.

Липкин, Михаил Аркадьевич. Глобальное прочтение истории СССР: дискуссии вокруг «Красной глобализации» Оскара Санчеса-Сибони // Российская история. 2016. № 1. С. 131-144.

Орлик, Игорь Иванович. СЭВ — «Общий рынок»: первые шаги к сближению двух интеграций // К 60-летию Совета экономической взаимопомощи. Единая Европа: прошлое и настоящее экономической интеграции. Москва: Институт экономики РАН, 2009. С. 223-238.

Широков, Олег Николаевич. СЭВ в мировой экономике: современные оценка и проблемы функционирования и значения. Вопросы истории, методологии и историографии. Москва: Институт научной информации по общественным наукам РАН, 2005. 154 с.

Comparativ: Zeitschrift fur Globalgeschichte und Vergleichende gesellschaftsforschung. Leipzig. 2017. Vol. 27. № 5-6: Comecon Revisited. Integration in the Eastern Bloc and Entaglements with the Global Economy. 198 p.

Crump, Laurien; Godard, Simon. Reassessing Communist International Organizations: A Comparative Analysis of COMECON and the Warsaw Pact in relation to their Cold War Competitors // Contemporary European History. 2017. Vol. 27 (1). Pp. 85-109.

Flade, Falk. Energy infrastructures in the Eastern bloc. Poland and the construction of transnational electricity, oil and gas transmission systems. A Thesis, submitted to the faculty of Business administration and economics of the European University Viadrina in Franfurt (Oder). Frankfurt (Oder): Otto Harrassowitz, 2017. 239 p.

Kansikas, Suvi. Socialist countries face the European Community. Soviet-bloc controversies over East-West trade. Frankfurt am Main: Peter Lang, 2014. 224 p.

Lipkin, Mikhail. A Struggle between Eastern and Western Models of «Integration» in the First Half of the 1970s // Quelle(s) Europe(s)? Nouvelles approches en histoire de l'intégration européenne / Ed. by Katrin Rucker \& Laurent Warlouzet. Brussels: P.I.E. Peter Lang, 2006. P. 299-310.

Mark, James; Rupprecht, Tobias. Matthias Middell (ed.). The Socialist World in Global History. From Absentee to Victim to Co-Produce // Matthias Middell (ed.) The Practice of Global History. European Perspectives, London: Bloomsbury, 2019. Pp. 81-114. (URL: https://www.academia.edu/37498808/The_Socialist World_in_Global_History._From_Absentee_to_Victim_to_Co-Producer (дата посещения — 20.07.2019))

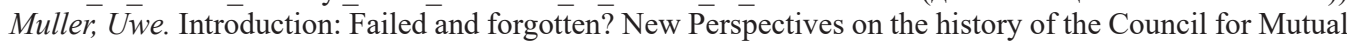
Economic Assistance // Comparativ: Zeitschrift fur globalgeschichte und vergleichende gesellschaftsforschung. 2017. Heft 5/6. P. 3-18.

Sanchez-Sibony, Oscar. Red Globalization. The political economy of the Soviet Cold War from Stalin to Khrustchev. Cambridge: Cambridge University Press, 2014. 294 p.

Stone, Randall W. Satellites and commissars: strategy and conflict in the politics of Soviet-block trade. Princeton: Princeton University Press, 1996. 283 p. 
Information about the article

The research was support by Russian Science Foundation, project Nr. 17-18-01728 (The "Socialist World System" and the Global Economy in the mid 1950s - mid 1970s: the Evolution of Theories and Practices of Soviet Economic and Technological Leadership)

Author: Lipkin, Mikhail Arkadyevich - Doctor in History, Corresponding member of the Russian Academy of Sciences, Director of the Institute of World History, Russian Academy of Sciences, Moscow, Russia, OrcID 0000-0002-7717-6392, ResearcherID R-9304-2016, ScopusID 57059972700, SPIN-код 2211-0732, e-mail: mli@igh.ru

Title: The Council for Mutual Economic Assistance and the existing trends in study of the $20^{\text {th }}$ century: towards the $70^{\text {th }}$ anniversary of CMEA

Summary: The article is dedicated to analysis of contemporary state of research in the field of institutional history of the Council for Mutual Economic Assistance (CMEA). The author analyzes various publications, dissertations and conference papers over the two last decades. He argues that after dissolution of CMEA in 1991 its history was wrongly forgotten. A new interest appeared in 2010-s as a result of few factors: social request for better understanding of the economic nature of East European countries, the advent of new methodological approaches and a new generation of historians. The CMEA research field passes threw a new stage of discovery what is a result not so much of new evidences and archival opening as with appearance of new wave of historians interested in objective study of CMEA phenomenon with a use of transnational and global history approaches, searching answers to the burning issues of contemporary world about possible alternatives to the capitalist globalization based on the institutions of Bretton-Woods model of the 20th century.

Keywords: CMEA, COMECON, planning economy, economic globalization, socialism, capitalism, Cold War, European integration, USSR, Eastern Europe, historiography, global history

\section{References:}

Comparativ: Zeitschrift fur Globalgeschichte und Vergleichende gesellschaftsforschung. 2017. Heft 5/6: Comecon Revisited. Integration in the Eastern Bloc and Entaglements with the Global Economy. 198 p.

Crump, Laurien; Godard, Simon. Reassessing Communist International Organizations: A Comparative Analysis of COMECON and the Warsaw Pact in relation to their Cold War Competitors, in Contemporary European History. 2017. Vol. 27 (1). Pp. 85-109.

Flade, Falk. Energy infrastructures in the Eastern bloc. Poland and the construction of transnational electricity, oil and gas transmission systems. A Thesis, submitted to the faculty of Business administration and economics of the European University Viadrina in Franfurt (Oder). Frankfurt (Oder): Otto Harrassowitz Publ., 2017. 239 p.

Gibianskiy, Leonid Yanovich. $\mathrm{K}$ istorii vozniknoveniya kollektivnykh struktur sovetskogo bloka: obrazovanie Soveta ekonomicheskoy vzaimopomoshchi [To the history of the emergence of the collective structures of the Soviet bloc: the formation of the Council for Mutual Economic Assistance], in Slavyanstvo, rastvorennoe $v$ krovi...: V chest' 80 -letiya so dnya rozhdeniya chlena-korrespondenta RAN V. K. Volkova (1930-2005). Moscow: Institute of Slavic Studies (RAS) Press, 2010. Pp. 325-348. (in Russian).

Kansikas, Suvi. Socialist countries face the European Community. Soviet-bloc controversies over East-West trade. Frankfurt am Main: Peter Lang Publ., 2014. 224 p.

Lipkin, Mikhail Arkadyevich. A Struggle between Eastern and Western Models of «Integration» in the First Half of the 1970s, in Rucker, Katrin; Warlouzet, Laurent (eds). Quelle(s) Europe(s)? Nouvelles approches en histoire de l'intégration européenne. Brussels: P.I.E. Peter Lang Publ., 2006. Pp. 299-310.

Lipkin, Mikhail Arkadyevich. Global'noe prochtenie istorii SSSR: diskussii vokrug «Krasnoy globalizatsii» Oskara Sanchesa-Siboni [A global reading of the history of the USSR: discussions around «red globalization» of Oskar Sanches-Siboni], in Rossiyskaya istoriya. 2016. No. 1. Pp. 131-144. (in Russian).

Lipkin, Mikhail Arkadyevich. «Mirovoy kooperativ narodov»: Sovet ekonomicheskoy vzaimopomoshchi, kotoriy pytalsya postroit N. S. Khrushchev [World Cooperative of People: The Council for Mutual Economic Assistance, which N. Khrushchev tried to build], in Noviy istoricheskiy vestnik. 2017. No. 4. Pp. 121-144. (in Russian).

Lipkin, Mikhail Arkadyevich. «My idem s otkrytym zabralom na razgovor s "Obshchim rynkom"»: Istoriya peregovorov SEV i YeES ob osnovakh otnosheniy v 1972-1979 godakh ["We are going with an open visor to talk with the Common Market.":The history of the CMEA and EEC negotiations on the foundations of relations in 1972-1979], in Noviy istoricheskiy vestnik. 2018. No. 4 (58). Pp. 101-135. (in Russian). 
Mark, James; Rupprecht, Tobias. Mark J., Rupprecht T. The Socialist World in Global History. From Absentee to Victim to Co-Produce, in Matthias Middell (ed.) The Practice of Global History. European Perspectives, London: Bloomsbury, 2019. Pp. 81-114. (URL: https://www.academia.edu/37498808/The_Socialist_ World_in_Global_History._From_Absentee_to_Victim_to_Co-Producer (last visited — July 20,2019)).

Müller, Uwe. Introduction: Failed and forgotten? New Perspectives on the history of the Council for Mutual Economic Assistance, in Comparativ: Zeitschrift fur globalgeschichte und vergleichende gesellschaftsforschung. 2017. Heft 5/6. Pp. 7-25.

Orlik, Igor' Ivanovich. SEV — «Obshchiy rynok»: pervye shagi k sblizheniyu dvukh integratsiy [CMEA "Common Market": the first steps towards bringing the two integration closer together], in $K$ 60-letiyu Soveta ekonomicheskoy vzaimopomoshchi. Edinaya Evropa: proshloe i nastoyashchee ekonomicheskoy integratsii. Moscow: Institute of Economics of Russain Acadimy of Science Press, 2009. Pp. 223-238. (in Russian).

Sanchez-Sibony, Oscar. Red Globalization. The political economy of the Soviet Cold War from Stalin to Khrustchev. Cambridge: Cambridge University Press, 2014. 294 p.

Shirokov, Oleg Nikolaevich. SEV v mirovoy ekonomike: sovremennye otsenka i problemy funktsionirovaniya $i$ znacheniya. Voprosy istorii, metodologii i istoriografii [CMEA in the global economy: modern evaluation and problems of functioning and significance. Questions of history, methodology and historiography]. Moscow: Institute of Scientific Information for Social Sciences of Russain Acadimy of Science Press, 2005. 154 p. (in Russian).

Stone, Randall W. Satellites and commissars: strategy and conflict in the politics of Soviet-block trade. Princeton: Princeton University Press, 1996. 283 p. 